\title{
Os Desafios do Bem-estar na América Latina, as Políticas de Igualdade de Gênero e as Respostas Governamentais para a "Crise do Cuidado"
}

\author{
Clarisse Paradis \\ Universidade da Integração Internacional da Lusofonia Afro-Brasileira
}

\section{Introdução}

A relação entre o feminismo e o Estado alimentou um debate profundo e ainda em desenvolvimento entre diversas perspectivas teóricas (Matos e Paradis, 2014). No que se refere ao Estado de BemEstar Social (EBES), as feministas se preocuparam extensivamente com as bases patriarcais deste modelo estatal, as consequentes formas de dependência feminina estimuladas por suas instituições, bem como as possibilidades de os regimes de bem-estar incorporarem maneiras de desafiar as desigualdades.

Dentre as desigualdades de gênero bastante conectadas com as diversas políticas e instituições estatais, está, sem dúvida, a divisão sexual do trabalho, entendida por Hirata e Kergoat (2007) como uma forma de divisão do trabalho decorrente das relações entre homens e mulheres, que "tem como características a designação prioritária dos homens à esfera produtiva e das mulheres à esfera reprodutiva e, simultaneamente, a apropriação pelos homens das funções com maior valor social adicionado (políticos, religiosos, militares, etc.)” (Hirata e Kergoat, 2007, p. 599).

A divisão sexual do trabalho produziu, historicamente, uma naturalização da responsabilização das mulheres pelas tarefas domésticas e cuidados, tornando-as invisíveis e desvalorizadas. Como afirma Tronto (1997), a atividade de cuidar é essencialmente relacional, evidenciando as relações de dependência que todos os seres humanos experimentam, em pelo menos um momento da vida. Ainda que o care $^{1}$ faça parte da vida de todas as pessoas, essa atividade é repartida de forma desproporcional e marcada por desigualdades de gênero, raça e classe (Hirata, 2010).

Como veremos, essa naturalização está na base do menor acesso das mulheres à renda, de sua inserção precarizada no mercado de trabalho e de vários problemas de saúde, especialmente a partir da exaustão pela falta de tempo livre, das dificuldades de acesso a uma educação continuada, dentre outros fatores.

Os sistemas de bem-estar social podem ser entendidos a partir de como influenciam as relações de gênero, especialmente, a maneira como as tarefas de provisão do bem-estar são divididas entre homens e mulheres, nas famílias e entre o mercado e o Estado. Os diversos arranjos dessa distribuição impactam diferentemente as relações de gênero e reproduzem ou desafiam a divisão sexual do trabalho.

No contexto latino-americano, a incorporação massiva das mulheres no trabalho remunerado,

\footnotetext{
${ }^{1}$ De acordo com Hirata (2010), o termo care é polissêmico e, portanto, não bem traduzido como cuidado. Refere-se a "cuidado, solicitude, preocupação com o outro, estar atento a suas necessidades" (Hirata, 2010, p. 43).
} 
as transformações no escopo da família nuclear e o envelhecimento da população são fatores que têm influenciado fortemente a divisão sexual do trabalho. A presença das mulheres no mercado de trabalho remunerado exige uma nova combinação das tarefas de bem-estar, fazendo com que as demandas por cuidado sejam maiores do que a disponibilidade de atendimento a elas no âmbito privado (pelas mulheres).

A crise do cuidado e a rígida divisão sexual do trabalho geram um dilema para os regimes de bem-estar da região, que como veremos, estão calcados no papel das famílias. Nesse sentido, resta saber se e como os governos buscaram planejar políticas públicas de bem-estar que enfrentassem esses problemas, e se essas soluções poderiam reforçar ou desconstruir as desigualdades de gênero.

Para tal, serão examinados os planos nacionais de igualdade de gênero de dez países da região - Brasil, Bolívia, Chile, Equador, Honduras, Paraguai, Peru, República Dominicana, Uruguai e Venezuela -, a partir da construção de uma tipologia que os caracterize segundo os tipos de soluções apresentadas para os diferentes dilemas sobre as relações de gênero e o provimento de bem-estar. Esses planos referem-se a diferentes períodos e foram mapeados no ano de $2013^{2}$.

Do ponto de vista teórico, o artigo buscará recuperar, brevemente, as críticas feministas ao Welfare State e os esforços teóricos de pensar as potencialidades deste sistema para a dissolução das hierarquias de gênero. Por esse frame, será possível analisar os desafios da agenda da igualdade de gênero latino-americana. Além disso, buscar-se-á (re)pensar as aplicações da noção de EBES para a América Latina e caracterizar os regimes latino-americanos de bem-estar, segundo a fonte do provimento do próprio bem-estar.

$\mathrm{O}$ artigo está dividido em três partes. A primeira seção busca expor a literatura feminista desenvolvida nessa área: os principais problemas identificados pelas autoras feministas na construção teórica do Welfare State, em seus fundamentos e nas instituições responsáveis por sua reprodução, bem como em estudos que combinaram as categorias mainstream e as referentes às relações de gênero.

A segunda seção buscará analisar o contexto latino-americano. A possibilidade de pensar a América Latina a partir da literatura do EBES é problematizada, bem como as transformações sociais, políticas e econômicas experimentadas ao menos nos últimos 15 anos na região. Utilizando-se uma tipologia de regimes de bem-estar, são analisados os desafios de gênero vigentes na região. Por fim, são avaliadas as respostas governamentais a esses desafios, a partir dos planos nacionais de igualdade de gênero.

\section{Crítica feminista ao estado de bem-estar social Euroamericano}

Assim como em outras áreas das ciências sociais, a inserção da perspectiva feminista no âmbito da pesquisa sobre Estado de Bem-Estar Social foi intermediada por consideráveis críticas e desconstruções, principalmente nos anos 1980 e 1990, trazendo para o campo novas e significativas hipóteses de trabalho (Myles e Quadagno, 2002). Teóricas como Gordon (1990), Pateman (1989), Orloff (1993 e 1996); Fraser (1989) identificaram que as premissas nas quais se assentavam a teoria sobre o EBES estavam marcadas por uma cegueira ao gênero, o que contribuía para formar uma teoria profundamente distorcida.

\footnotetext{
${ }^{2}$ Em alguns países, os planos já foram substituídos por novas versões ou mesmo expiraram, sem a sua substituição. No entanto, essas mudanças não puderam ser mapeadas no escopo deste trabalho.
} 
Nessa perspectiva, o trabalho de Esping-Andersen foi revisado por autoras como Orloff (1993) e, a partir das críticas produzidas, o próprio autor reformulou sua teoria. Seu desenvolvimento teórico parte das premissas da abordagem dos recursos de poder, isto é, para analisar o EBES é preciso perceber a forma de mobilização das classes sociais, a estrutura de coalizão das classes políticas, bem como o processo histórico de institucionalização do bem-estar (Esping-Andersen, 1990). Com esses enunciados, o autor analisa a luta de classes democráticas a partir de dois conceitos desmercadorização e estratificação social. O primeiro se refere à opção de indivíduos e famílias:

[...] manterem um padrão de vida aceitável independentemente da participação no mercado. Na história das políticas sociais, os conflitos geralmente se travaram em torno do nível permissível ao indivíduo de isenção do mercado, isto é, da capacidade, alcance e qualidade dos serviços sociais. Quando o trabalho está mais perto da livre escolha do que da necessidade, a desmercadorização pode significar desproletarização (Esping-Andersen, 1990, p. 37, tradução nossa).

A desmercadorização é, portanto, um requisito de cidadania em que os trabalhadores podem decidir livremente se desejam trabalhar ou não e sob quais condições (Cardoso Jr., 2003). Seu desenvolvimento está relacionado à forma de estratificação, o que significa que o Estado de BemEstar influencia ativamente a ordem das relações entre Estado, mercado e família.

Conforme Esping-Andersen (1990), ao estudar os regimes de bem-estar social, é fundamental responder a uma questão: qual sistema de estratificação é produzido pelas políticas sociais? Segundo ele, "o Estado de Bem-Estar Social não é somente um mecanismo que intervém na, e possivelmente corrige, a estrutura de desigualdade; é, no seu próprio termo, um sistema de estratificação. É uma força ativa no ordenamento das relações sociais" (Esping-Andersen, 1990, p. 23, tradução nossa). Assim, os diferentes regimes de bem-estar distinguem-se pelo grau de desmercadorização da força de trabalho e o modo de estratificação.

Os regimes são classificados em "liberal", "conservador ou corporativista" e "socialdemocrata". O primeiro refere-se aos países norte-americanos e caracteriza-se por uma assistência focada nos comprovadamente carentes. Os cidadãos são vistos como atores individuais e há um incentivo do Estado para que os benefícios do bem-estar sejam adquiridos no mercado. $O$ nível de desmercadorização é baixo, e o de estratificação, "é um misto de uma relativa igualdade na pobreza entre os beneficiários do sistema, proteção diferenciada pelo mercado para as maiorias e um dualismo político de classe entre os dois" (Esping-Andersen, 1990, p. 27, tradução nossa).

O regime conservador descreve os países da Europa Continental e refere-se a um tipo de benefício que não se apoia no mercado, mas é envolvido na manutenção da ordem social hierárquica do passado (Myles e Quadagno, 2002). É corporativista, na medida em que os direitos e benefícios estão associados às diferentes classes e status. Sua redistribuição é marginal e o lócus primordial do bem-estar está na família.

Por fim, o regime socialdemocrata aparece nos países da Escandinávia e possui princípios universalistas de difusão do bem-estar. Ao contrário do liberal, o papel do mercado na provisão da seguridade social é mínimo e os direitos sociais são bastante amplos. Há uma grande preocupação com a redistribuição e o aumento da renda, de modo que "todos se beneficiam; todos são dependentes 
e todos supostamente se sentirão no dever de contribuir" (Esping-Andersen, 1990, p. 28, tradução nossa).

Orfloff (1993) criticou no modelo de Sping-Andersen a concepção da figura do homem trabalhador como o ideal de cidadão e apontou uma ausência de consideração sobre as diferenças de gênero no interior das classes sociais e o trabalho das mulheres no interior da família. Além disso, indicou problemas na aplicação do conceito de desmercadorização para compreender as mulheres. Segundo ela, Esping-Andersen:

[...] vê as mulheres como escolhendo entre ser trabalhadora ou dona de casa, sendo o trabalho no mercado somente possível para as mulheres se os serviços públicos são amplamente disponíveis. [...]. Nenhuma mulher casada e mãe no ocidente industrializado pode escolher não se engajar no trabalho do cuidado, a não ser que seja rica o suficiente para pagar por esse serviço (Orloff, 1993, p. 313, tradução nossa).

Em sua obra de 1999, "Fundações sociais das economias pós-industriais”, Esping-Andersen incorporou algumas das críticas feministas, incluindo o conceito de "desfamilização", entendido como o sistema de bem-estar que busca atenuar a dependência das mulheres às relações familiares tradicionais. Segundo o autor, um regime seria familista quando ele assume o núcleo familiar como lócus primordial do bem-estar das pessoas.

Apenas o regime socialdemocrata teria desenvolvido alguma política estruturada de desfamilização, enquanto que nos regimes liberais e conservadores imperariam formas de desfamilização não orquestradas pelo Estado, como a diminuição da taxa de fecundidade por escolha das mulheres, jornadas de trabalho menores e flexíveis, aumento da renda familiar, possibilitando a compra de serviços sociais, etc. ${ }^{3}$.

Além das críticas ao trabalho de Esping-Andersen, as autoras feministas buscaram identificar distorções na lógica dos sistemas de bem-estar, que acabariam perpetuando a desigualdade de gênero neste formato de Estado, baseando-se numa rígida divisão sexual do trabalho.

Como nos mostra Gordon (1990), o EBES fundamentou-se no modelo de família "homem provedor/ mulher dona de casa", reforçado pelo "salário-família", em que a base de pagamento dos trabalhadores leva em conta a necessidade do provedor sustentar a esposa e os filhos, e não o valor necessário para a sua própria reprodução, reforçando a dependência das mulheres e gerando distorções salariais importantes entre homens e mulheres, no mercado de trabalho.

Além disso, conforme apontam Pateman (1989) e Gordon (1990), o EBES não rompeu com o traço fundamental dos Estados modernos, de rígida divisão do âmbito público e privado. Nesse sentido, o EBES também tem base patriarcal, assegurando que as mulheres provenham serviços sociais gratuitos no interior das famílias, vistos não como trabalho, mas como tarefas inerentes ao papel que ocupam na vida privada.

Fraser (1989) desenvolveu uma interessante abordagem para pensar politicamente o

\footnotetext{
${ }^{3}$ Nota-se, no entanto, que algumas dessas formas de desfamilização "alternativas" não rompem, muitas vezes, com a precária inserção das mulheres no mercado de trabalho, nem com a divisão sexual do trabalho ou desigualdades de raça e classe.
} 
funcionamento do Estado de Bem-Estar. Segundo ela, o discurso hegemônico desse regime trata as necessidades das pessoas como algo autoevidente e localizado além da disputa. Dessa forma, as normas e suposições implícitas dos sistemas moldam as práticas do Welfare e devem ser pensadas como "padrões institucionalizados de interpretação das necessidades" (Fraser, 1989, p. 146).

Apesar de todas as críticas à teoria e ao funcionamento dos Welfare States, algumas autoras buscaram identificar quais elementos contidos no EBES poderiam desafiar a desigualdade de gênero e garantir as bases da cidadania das mulheres. Orloff (1993) critica a reprodução do funcionalismo em algumas análises feministas, quando afirmam que o EBES reforça as relações de dominação e exploração sobre as mulheres, sendo funcional para o patriarcado e o capitalismo. Nesse sentido, Pateman (1989) aponta que mesmo que o EBES leve em conta a mulher como dependente do homem, ele cria benefícios que podem tornar as mulheres economicamente independentes.

Frances Fox Piven (1990), em sua análise sobre o sistema de bem-estar americano, aponta o potencial de ação política das mulheres, dado o seu envolvimento na estrutura do EBES, que seria reforçado pela potencial aliança entre mulheres de diferentes classes sociais. As trabalhadoras teriam mais acesso à educação e pertenceriam às classes médias, mas estariam estruturalmente ligadas às mulheres pobres, maiores beneficiárias desse sistema. A autora argumenta, ainda, que a estrutura do EBES ajudaria a criar novas estratégias e formas de solidariedade intragênero, produzindo novas questões políticas que as cimentariam e estimulariam.

Algumas autoras se engajaram nos estudos comparativos dos regimes de bem-estar. Segundo Sainsbury (2008), três estratégias foram utilizadas para tornar "engendradas" a pesquisa comparativa no campo: “(1) a utilização das construções analíticas existentes para analisar gênero e o Welfare State; (2) o redesenho das construções analíticas, de modo a possibilitar uma significativa análise de gênero; (3) o desenvolvimento de novas estruturas analíticas e dimensões conceituais" (Sainsbury, 2008, p. 100).

Sainsbury (1996) utilizou uma série de dimensões de variação para criar uma tipologia de EBES que levasse em conta as relações de gênero. Dentre as variáveis utilizadas, estão: a ideologia de gênero e familismo, princípios que organizam o direito aos benefícios sociais; o sistema tributário; políticas de emprego e salário; a organização do trabalho de cuidado. Ao analisar a Holanda, Suécia, Inglaterra e Estados Unidos, a autora encontrou três tipos de regimes, segundo as políticas de gênero: regime do homem provedor, regime dos papéis separados de gênero e regime do indivíduo provedor/cuidador (Sainsbury, 1996). O primeiro está fundamentado na estrita divisão sexual do trabalho, o segundo também se baseia nesta divisão, mas reconhece os direitos da mulher enquanto cuidadora e, o último, baseia-se no compartilhamento das funções de provimento e cuidado entre homens e mulheres.

Orloff (1993), por sua vez, procurou aportar a perspectiva de gênero nos regimes de bem-estar de Esping-Andersen. Mais do que criar outras tipologias, a autora buscou reformular os conceitoschave do autor - desmercadorização e estratificação social - e adicionar duas outras dimensões para análise: o acesso ao trabalho remunerado e a capacidade das mulheres de formarem e manterem uma unidade familiar autônoma.

A dimensão do acesso ao trabalho remunerado é importante na percepção do processo de mercadorização para as mulheres. Como afirma Orloff, "para muitas mulheres e outros excluídos do trabalho remunerado, a mercadorização, isto é, obter uma posição no mercado de trabalho, é um fato potencialmente emancipador. A remuneração provê independência para as mulheres" (Orloff, 1993, 
p. 318, tradução nossa). Assim, essa nova dimensão deve medir o modo como o Estado promove ou desencoraja o trabalho remunerado das mulheres.

A segunda nova dimensão indica a habilidade dos responsáveis por grande parte do trabalho do cuidado e remunerado (quase todos são mulheres), de formar e manter uma família autônoma. Significa perceber se esses/as cuidadore/as são capazes de sobreviver e dar suporte às suas crianças, sem ter de se casar para ter acesso à renda do provedor (Orloff, 1993, p. 320)

Mais recentemente, Fraser (2016) situou o contexto do capitalismo fordista como marcado pelo EBES euro-americano, assumindo a responsabilidade da reprodução, no sentido de combater o desemprego massivo, assegurar consumidores e garantir engrenagens da economia capitalista. Foi forjada, então, uma nova síntese entre mercantilização e proteção social, que provocou, de um lado, avanços democráticos, mas, de outro, baseou-se na exploração da periferia, na hierarquia racial e no modelo heteronormativo de família sexista.

Atualmente, a autora reconhece transformações, especialmente a partir de uma nova fase do capitalismo, marcada pela financeirização. Nesse período, uma economia de trabalhos precários, marcada pelo desmonte das forças corporativas e estatais de provimento do bem-estar, levou a uma organização dualizada da reprodução social - comprada no mercado ou fornecida gratuitamente, no interior das famílias (especialmente pelas mulheres).

Na seção seguinte, o EBES latino-americano será caracterizado e, posteriormente, tipificado, a partir do desenvolvimento teórico de Franzoni (2007), no esforço de produzir uma tipologia dos regimes de bem-estar latino-americanos, segundo os conceitos de mercadorização, desmercadorização, familiarização e desempenho no manejo dos riscos.

\section{O Estado de bem-estar Latino Americano no século XXI e seus desafios para alcançar a igualdade de gênero}

Como afirmam Draiber e Riesco (2006), os estudos que levam em conta o conceito de Estado de Bem-Estar Social para analisar o contexto latino-americano ainda são escassos. Isso porque, durante muito tempo, o EBES foi postulado como uma instituição pertencente exclusivamente aos países desenvolvidos, principalmente europeus. Além disso, os estudos latino-americanos sobre proteção social, salvo algumas exceções, têm sido desenvolvidos a partir do enfoque em programas, áreas e setores específicos, sendo entendidos de maneira fragmentada e não como um sistema (Draiber e Riesco, 2006). Essa fragmentação é mais reforçada ainda, em nome da especificidade das realidades de cada país da região.

$\mathrm{Na}$ contramão dessa tendência, os autores têm despendido esforços para pensar as bases do Estado de Bem-Estar latino-americano. Para eles, o que se formou na região foi um tipo de Estado desenvolvimentista de Bem-Estar que, mesmo emerso de modo irregular entre os países, moldou os sistemas nacionais de proteção social no período de 1930 a 1980 (Draibe e Riesco, 2011).

O paradigma neoliberal, dominante na região no final dos anos 1980 e 1990, mas com fortes ecos atuais, contribuiu para o declínio do Estado desenvolvimentista de Bem-Estar. Novos serviços sociais passaram a ser oferecidos de maneira privada, atendendo apenas aqueles que podiam pagar,

\footnotetext{
${ }^{4}$ Como vimos anteriormente, o desenvolvimento analítico dessas autoras influenciou a inclusão do conceito de familiarização na análise de Esping-Andersen, em sua obra de 1999.
} 
enquanto os setores médios ficaram desprotegidos, trabalhando em empregos cada vez mais precários (Draibe e Riesco, 2009).

A passagem para o século XXI foi acompanhada por transformações econômicas, sociais e políticas na América Latina. A partir do final do século XX e até meados da sua década, o clima político da região foi marcado por críticas às soluções neoliberais. Os resultados sociais desastrosos da adoção desse sistema, juntamente com uma pressão perene dos movimentos sociais e partidos progressistas, que se gabaritaram como fortes opções eleitorais, levaram a um reforço da busca por novas alternativas para a região, que combinassem crescimento econômico, aprofundamento da democracia e justiça social ${ }^{5}$.

Essa nova agenda social da América Latina, segundo Draibe e Riesco, parece ter se desdobrado em um novo modelo de Estado desenvolvimentista de Bem-Estar na região. Segundo os autores, várias inovações foram propostas no âmbito dos sistemas de proteção social latino-americano, especialmente a partir de visões mais amplas sobre inclusão social, peso dos programas de transferência de renda direta ou condicionada às famílias pobres, formas mais descentralizadas de políticas sociais, instituições participativas, etc.

Franzoni (2007) produziu uma tipologia dos regimes de bem-estar latino-americanos segundo o grau de mercadorização da força de trabalho (refletindo a capacidade do mercado de trabalho em prover trabalho formal remunerado), o grau de desmercadorização do bem-estar (sua autonomia em relação ao mercado, devido à redistribuição de recursos de políticas públicas), o grau de familiarização do bem-estar (autonomia entre a disponibilidade de trabalho feminino não remunerado, baseado na divisão sexual do trabalho) e, por fim, o desempenho no manejo dos riscos (o resultado em termos de melhores ou piores condições de vida da população) (Franzoni, 2007).

A partir de modelos estatísticos, a autora encontrou três tipos de regimes na América Latina vigentes naquele período, conforme quadro abaixo:

Quadro 1 - Regimes de Bem-Estar na América Latina

\begin{tabular}{|c|c|}
\hline Regimes de Bem-Estar & Países \\
\hline Estatal-produtivista & Argentina e Chile \\
\hline Estatal-protecionista & $\begin{array}{c}\text { Brasil, Costa Rica, México, Panamá e } \\
\text { Uruguai }\end{array}$ \\
\hline \multirow{2}{*}{ Familiarista } & \begin{tabular}{c} 
Colômbia, Equador, El Salvador, Guatemala, \\
Peru, República Dominicana e Venezuela \\
\cline { 2 - 3 }
\end{tabular} \\
$\begin{array}{c}\text { Subgrupo altamente familiarista: } \\
\text { Bolívia, Honduras, Nicarágua e Paraguai }\end{array}$ \\
\hline
\end{tabular}

Fonte: Elaboração própria, a partir do modelo elaborado por Franzoni (2007).

O primeiro cluster é caracterizado por políticas públicas que enfatizam a formação de capital humano, com menor ênfase na desmercadorização da seguridade social e intervenções do Estado nas

\footnotetext{
${ }^{5}$ Típicos desse momento foram os governos do Brasil, Argentina, Venezuela, Bolívia, Equador, entre outros. Apesar de processos muitos distintos terem se desenvolvido em cada um desses países, todos seus governantes foram eleitos a partir de programas que desafiavam (mais ou menos) os preceitos neoliberais. Não faz parte do escopo deste artigo analisar os processos de deslegitimação desses governos no contexto atual, algo que, sem dúvida, deve ser pensado à luz dos discursos sobre o papel do Estado no provimento de bem-estar.
} 
áreas em que o mercado não resolve (Franzoni, 2007, p. 24). O setor privado tem papel central na provisão do bem-estar. Nos países do segundo cluster, o Estado intervém em áreas que poderiam ser de domínio do mercado e para a população que não necessariamente encontra-se na pobreza (Franzoni, 2007, p. 24). É um regime protecionista, pois mantém, de alguma forma, papéis importantes do Estado intervencionista no modelo de substituição de importações. Em ambos clusters, o trabalho não remunerado, exercido pelas mulheres em tempo integral, é componente importante do provimento de bem-estar (Franzoni, 2007).

O terceiro grupo é dominado por práticas de produção informal, possui mercados de trabalho e políticas públicas excludentes, poucos têm acesso a serviços públicos e a família é a grande responsável pelo bem-estar das comunidades (Franzoni, 2007). No subgrupo dos altamente familiaristas, as organizações internacionais têm maior papel na segurança social do que o Estado. O papel do trabalho não remunerado no interior da família, para a provisão de bem-estar, é o maior dentre os três grupos (Franzoni, 2007, p. 28).

Por fim, a autora conclui que ambos os regimes são, em grande medida, informais, contendo mercados de trabalho ineficientes e políticas públicas débeis. A desfamilização é pouco acentuada e predomina a divisão sexual do trabalho (Franzoni, 2007, p. 30). Quanto mais informal é o regime, maior a carga de trabalho gratuito das mulheres, já que este visa "compensar" a falta de serviços públicos.

Apesar de empreender algo desafiador - construir padrões analíticos em contexto tão heterogêneo e um modelo que dificilmente capta todas as transformações nos países -, a análise da autora parece ser útil para aprofundar a noção de Estado de Bem-Estar da região e possibilitar reflexões sobre os desafios que deverá enfrentar, principalmente no que se refere à relação entre trabalho remunerado e não remunerado e a autonomia das mulheres.

Alguns dados corroboram esses achados. A cobertura de atenção da educação infantil ainda é bastante deficitária na região. Conforme dados da CEPAL (2009, p. 46), a cobertura educacional de crianças de 3 a 5 anos é muito menor do que na educação básica. Na Guatemala, Honduras e El Salvador (regime familiarista), a cobertura não atinge nem $30 \%$ das crianças, enquanto na Costa Rica, Nicarágua e Peru não chega a 50\%. Entre os países com dados disponíveis, Uruguai tinha a maior cobertura, com $74 \%$ (dados referentes a meados de 2007 ).

Essa situação é ainda mais desafiante diante das transformações sociais e demográficas vividas pelos países da região, que, segundo a CEPAL (2009), começam a gerar uma crise do cuidado. As mulheres têm participação cada vez mais elevada nos trabalhos remunerados, a divisão sexual do trabalho continua rígida, aumentam as famílias monoparentais, faltam mecanismos estatais e de mercado que assumam as tarefas reprodutivas e aumenta a demanda da população que requer cuidados, devido ao seu envelhecimento, à manutenção das altas taxas de fecundidade e ao aumento das pessoas com doenças crônicas (CEPAL, 2009, p. 36).

O gráfico abaixo demonstra o crescimento substancial da participação das mulheres no mercado de trabalho na América Latina. Desde 1997, a maioria das mulheres exerce algum tipo de trabalho remunerado. 


\section{Gráfico 1 - Participação e emprego de mulheres de 25 a 54 anos, em porcentagem - América Latina (média ponderada de 15 países), 1990-2007}

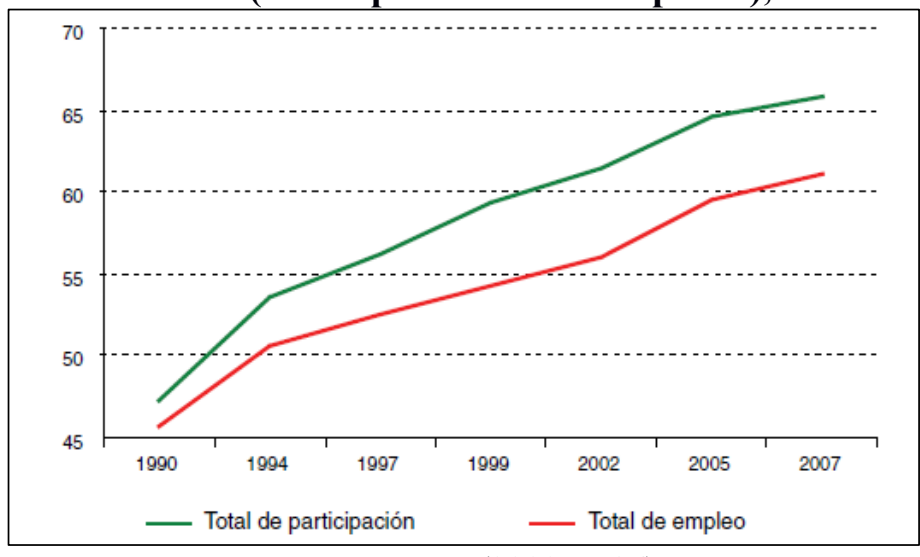

Fonte: CEPAL (2009, p. 36).

No entanto, como afirmado anteriormente, essa participação não significou uma socialização do trabalho não remunerado, mas o acúmulo de ambos, contribuindo para a inserção precária das mulheres no mercado de trabalho. Elas já são maioria no setor informal e nos serviços de tempo parcial, o que contribui para sua vulnerabilidade e baixa renda.

Combinado com essa situação, está o crescente envelhecimento da população, que torna a vulnerabilidade das mulheres ainda maior. O gráfico abaixo demonstra que o próximo período será marcado por uma queda da fecundidade e um aumento significativo da população idosa.

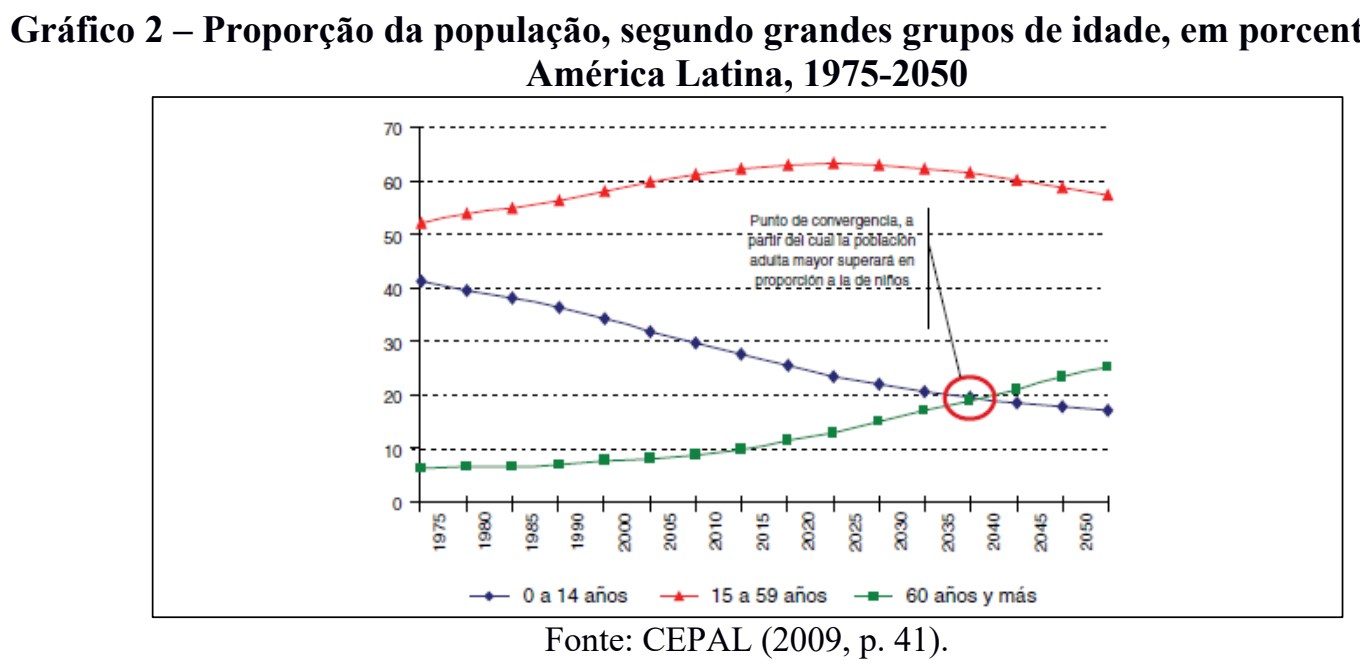

A crise do cuidado e a rígida divisão sexual do trabalho geram um dilema para os regimes de bem-estar da região, que, como citado anteriormente, estão calcados no papel das famílias. Do mesmo modo que os sistemas de bem-estar dos países centrais, também vistos anteriormente, foram construídos a partir do modelo familiar "homem-provedor/mulher dona de casa", os sistemas latinoamericanos têm reproduzido esta premissa. Apesar de serem visões cada vez mais questionadas, falta consenso sobre a socialização do trabalho não remunerado e as formas de atingir a igualdade entre homens e mulheres.

Na próxima seção, vamos examinar os planos nacionais de igualdade de gênero, com o objetivo de verificar as respostas que os Estados latino-americanos têm construído para os dilemas entre 
produção e reprodução, apontados acima.

\section{0 reconhecimento do trabalho reprodutivo não remunerado, exercido pelas mulheres, através dos discursos, políticas e planejamento estatais}

É importante fazer uma ressalva quanto à ideia de crise do cuidado. Só recentemente, a questão do cuidado passou a ser vista como um problema político que exige a atenção dos governos. Isso acontece quando a disponibilidade das mulheres para exercer gratuitamente esse trabalho se torna menor, na mesma medida em que cresce a demanda por ele. Nesse contexto, o termo não leva em conta que a desproporcional responsabilidade do cuidado, historicamente exercida pelas mulheres, é algo por si só insustentável e perverso, que gera efeitos nocivos para o acesso das mulheres à renda, saúde, trabalho, educação, etc. Assim, é possível concluir que o cuidado foi sempre uma crise, ao menos para as mulheres.

Nesse sentido, segundo Sonia Montaño (2011), além da incompatibilidade entre a demanda social de cuidado e os recursos humanos disponíveis para tal, os processos de emancipação das mulheres e o reconhecimento dos direitos de grupos (como pessoas com deficiência) contribuíram para que, recentemente, houvesse maior preocupação dos governos em oferecer serviços de cuidado.

Segundo a autora, vivemos uma mudança de paradigma nesse campo que revela sinais importantes, ainda que não esteja consolidada. A partir da década de 1970, durante o período ditatorial na América Latina, as iniciativas de socialização do cuidado tinham forte enfoque familista e exploravam o cuidado das mulheres como um dom natural, orquestradas por instituições sociais de mulheres para o cuidado ou, muitas vezes, pelas primeiras damas (Montaño, 2011).

Paralelamente, várias formas de organizações populares e comunitárias surgem como resposta à falta de provisão pública da reprodução da vida, tanto durante as ditaduras militares quanto nos períodos de adoção do neoliberalismo. São as cozinhas populares no Chile e no Peru, as creches comunitárias nos bairros periféricos dos centros urbanos no Brasil, os clubes de mães na Bolívia, entre outros (Montaño, 2011).

O ciclo progressista na América Latina foi marcado por um relativo reconhecimento estatal da socialização do trabalho de reprodução, como elemento importante da busca por igualdade de gênero, a partir de novas legislações, reforço das estatísticas, políticas públicas, etc. (Montaño, 2011).

É possível perceber como os contornos familistas do bem-estar na região conviveram com esses contornos de mudança, a partir dos planos de igualdade de gênero dos governos. Para a análise, foram examinados planos de dez países da região, conforme quadro abaixo. 


\begin{tabular}{|l|l|l|}
\hline País & Quadro 2 - Planos de Igualdade de Gênero, América Latina & $\begin{array}{l}\text { Ano ou } \\
\text { Vigência }\end{array}$ \\
\hline Brasil & II Plano Nacional de Política para as Mulheres & 2008 \\
\hline Bolívia & Plan Nacional Para Igualdad de Oportunidades & 2008 \\
\hline Chile & Plan de Igualdad entre Mujeres y Hombres & $2010-2020$ \\
\hline Equador & $\begin{array}{l}\text { Plan de Igualdad, No discriminación y Buen Vivir para Las Mujeres } \\
\text { Ecuatorianas }\end{array}$ & $2010-2014$ \\
\hline Honduras & II Plan de Igualdad y Equidad de Género de Honduras & $2010-2022$ \\
\hline Paraguai & Plan Nacional de Igualdad de Oportunidades entre Mujeres y Hombres & $2008-2017$ \\
\hline Peru & Plan Nacional de Igualdad de Oportunidades entre Mujeres y Varones & $2006-2010$ \\
\hline $\begin{array}{l}\text { Rep. } \\
\text { Dominicana }\end{array}$ & II Plan Nacional de Igualdad y Equidad de Género & $2007-2017$ \\
\hline Uruguai & Primer Plan Nacional de Igualdad de Oportunidades y Derechos & $2007-2011$ \\
\hline Venezuela & Plan de Igualdad para las Mujeres & $2004-2009$ \\
\hline
\end{tabular}

Fonte: Elaboração própria.

Não foram incluídos na análise os países que contam apenas com uma política ou programa de igualdade de gênero, porque, muitas vezes, são instrumentos restritos aos governos vigentes que não têm a pretensão dos planos, de estabelecer prioridades, objetivos, ações ou metas de longo prazo. Mesmo que a implementação dos planos seja ainda hoje deficitária, eles expressam um amplo compromisso do Estado com a redução das desigualdades de gênero.

Todos os planos analisados enquadram, de alguma forma, o trabalho reprodutivo não remunerado exercido pelas mulheres como um problema, e preveem ações relacionadas a ele. Apenas o plano chileno se refere à crise do cuidado e possui um eixo exclusivo para a "corresponsabilidade social no cuidado familiar" (Chile, 2010, p. 42). Segundo o plano:

[...] outra modificação que impactou a estrutura familiar é que hoje um de cada 10 habitantes é maior que 60 anos. Para 2025, as estimativas indicam que uma de cada cinco pessoas estará nessa classificação, sendo as mulheres as que estarão mais representadas, dada sua maior esperança de vida. Isso mostra que as necessidades de cuidado de pessoas crescerão e que a demanda dos serviços de saúde das mulheres aumentará dramaticamente, especialmente no setor público (Chile, 2010, p.13).

Quatro tipos de ações são propostas pelos planos, no que se refere ao trabalho reprodutivo não remunerado: (1) ações que tornam visível o trabalho doméstico e de cuidado, a divisão sexual do trabalho e a contribuição do trabalho exercido pelas mulheres nas economias nacionais; (2) ações que visam socializar o trabalho reprodutivo com os homens, a partir da instalação de equipamentos públicos ou comunitários; (3) ações que visam criar ou fazer valer legislação específica do tema; (4) ações que visam sensibilizar para as transformações dos papéis tradicionais de gênero e a desvalorização do trabalho exercido pelas mulheres, tendo a igualdade de gênero como ideal normativo.

Dentre as ações de visibilidade, destaca-se a produção de dados estatísticos e pesquisas do uso do tempo - conforme demonstra Montaño (2011) - que evidenciem a contribuição do trabalho reprodutivo para as economias nacionais. Metade dos países prevê essas ações (Bolívia, Chile, 


\section{Honduras, Paraguai e Uruguai).}

Dez tipos de ações de socialização são propostos pelos diferentes planos, com destaque para a implementação de serviços públicos ou comunitários de cuidado das crianças - sete dos dez países propõem esta ação. Já os serviços públicos ou comunitários de cuidado aos idosos e pessoas com deficiência ou doença crônica são propostos por quatro dos sete países. Isso pode sugerir que, de um lado, a socialização do trabalho de reprodução é uma preocupação dos governos na região, e de outro, que ainda está concentrada no cuidado das crianças.

A construção de restaurantes e cozinhas populares é proposta apenas pelo Brasil e Equador, e a construção de lavanderias públicas somente pelo último. No que se refere às mudanças ou o reforço na legislação, destaca-se a inclusão das trabalhadoras não remuneradas nos sistemas de seguridade social, proposta por quatro países (Brasil, Equador, Honduras e Venezuela).

Quatro países propõem mudanças na licença paternidade ou a inclusão de legislação referente à paternidade responsável. Por fim, as ações de sensibilização mais gerais, que visam mudar valores, normas culturais, etc., são propostas por seis países. O quadro abaixo resume as ações classificadas nos quatro tipos e lista os países que preveem tais ações no âmbito dos seus planos de igualdade de gênero:

\begin{tabular}{|c|c|c|}
\hline $\begin{array}{l}\text { Tipos de } \\
\text { ações }\end{array}$ & Ações & Países \\
\hline \multirow{4}{*}{ Visibilidade } & $\begin{array}{l}\text { 1. Medir e quantificar, através de pesquisas, estudos, produção de dados } \\
\text { estatísticos, a contribuição do trabalho de reprodução não remunerado, exercido } \\
\text { pelas mulheres, nos censos nacionais e nos dados econômicos. }\end{array}$ & \begin{tabular}{|c|} 
Bolívia; Chile; \\
Honduras; Paraguai; \\
Uruguai \\
\end{tabular} \\
\hline & $\begin{array}{l}\text { 2. Desenvolver pesquisas do uso do tempo, revelando as diferenças entre o } \\
\text { exercício do trabalho remunerado e não remunerado, entre homens e mulheres. }\end{array}$ & $\begin{array}{l}\text { Chile; Honduras; } \\
\text { Paraguai }\end{array}$ \\
\hline & $\begin{array}{l}\text { 3. Remuneração para pessoas que realizam o trabalho de reprodução não } \\
\text { remunerado. }\end{array}$ & Equador; Venezuela \\
\hline & $\begin{array}{l}\text { 4. Revisar a categoria de "inativas" para pessoas que realizam o trabalho de } \\
\text { reprodução não remunerado. }\end{array}$ & Paraguai \\
\hline \multirow{10}{*}{ Socialização } & $\begin{array}{l}\text { 1. Implementar, fortalecer, ampliar, reformar os serviços públicos e } \\
\text { comunitários de atenção e cuidado das crianças, tais como creches, berçários ou } \\
\text { centros de cuidado infantil. }\end{array}$ & $\begin{array}{l}\text { Brasil; Bolívia; Chile; } \\
\text { Equador; Paraguai; } \\
\text { República } \\
\text { Dominicana; Uruguai }\end{array}$ \\
\hline & $\begin{array}{l}\text { 2. Implementar, fortalecer, ampliar, reformar os serviços públicos e } \\
\text { comunitários de atenção e cuidado aos idosos, pessoas com deficiência e com } \\
\text { doenças crônicas. }\end{array}$ & $\begin{array}{l}\text { Bolívia; Chile; } \\
\text { Equador; Uruguai }\end{array}$ \\
\hline & $\begin{array}{l}\text { 3. Implementar, fortalecer, ampliar os serviços de atenção e cuidado das } \\
\text { crianças em locais de trabalho, administrações públicas e centros de estudo. }\end{array}$ & $\begin{array}{l}\text { Chile; Equador; } \\
\text { Honduras; Paraguai; } \\
\text { Venezuela }\end{array}$ \\
\hline & $\begin{array}{l}\text { 4. Implementar, fortalecer, ampliar os serviços de atenção e cuidado de idosos, } \\
\text { pessoas com deficiência e com doenças crônicas, nos locais de trabalho }\end{array}$ & Honduras \\
\hline & $\begin{array}{l}\text { 5. Reorganizar, ampliar, adequar o funcionamento e horário dos serviços } \\
\text { públicos que atendem às necessidades de homens e mulheres. }\end{array}$ & $\begin{array}{l}\text { Chile; Equador; } \\
\text { Uruguai }\end{array}$ \\
\hline & $\begin{array}{l}\text { 6. Reorganizar, ampliar, adequar o funcionamento e horário dos serviços } \\
\text { privados que atendem às necessidades de homens e mulheres. }\end{array}$ & Equador \\
\hline & 7. Implementar, fortalecer, ampliar os Restaurantes e Cozinhas Populares. & Brasil; Equador \\
\hline & 8. Implementar, fortalecer, ampliar lavanderias públicas. & Equador \\
\hline & 9. Construir cisternas para captação da água da chuva. & Brasil \\
\hline & 10. Ampliar a jornada escolar. & Chile \\
\hline
\end{tabular}




\begin{tabular}{|c|c|c|}
\hline $\begin{array}{l}\text { Tipos de } \\
\text { ações }\end{array}$ & Ações & Países \\
\hline \multirow{5}{*}{$\begin{array}{c}\text { Reforço ou } \\
\text { mudança no } \\
\text { ordenamento } \\
\text { jurídico }\end{array}$} & $\begin{array}{l}\text { 1. Elaborar ou pressionar para aprovação de legislação que prevê seguridade } \\
\text { social para trabalhadora reprodutiva não remunerada. }\end{array}$ & $\begin{array}{l}\text { Brasil; Equador; } \\
\text { Honduras; Venezuela }\end{array}$ \\
\hline & $\begin{array}{l}\text { 2. Elaborar lei ou transformar legislação vigente, de modo a garantir a licença } \\
\text { paternidade, a "licença parental familiar", a responsabilidade paterna no } \\
\text { trabalho reprodutivo ou a igualdade de licença entre homens e mulheres. }\end{array}$ & $\begin{array}{l}\text { Chile; Peru; Uruguai; } \\
\text { Venezuela }\end{array}$ \\
\hline & 3. Legislar para ampliação da licença maternidade. & $\begin{array}{l}\text { Chile; República } \\
\text { Dominicana }\end{array}$ \\
\hline & $\begin{array}{l}\text { 4. Ratificação do Convênio } 156 \text { da OIT sobre trabalhadores e trabalhadoras } \\
\text { com responsabilidades familiares. }\end{array}$ & Honduras \\
\hline & $\begin{array}{l}\text { 5. Legislar para estabelecer o direito ao cuidado para pessoas dependentes } \\
\text { (idosos/as e com deficiência severa) a serem protegidas pelo Estado e } \\
\text { garantidos os serviços correspondentes. }\end{array}$ & Chile \\
\hline \multirow{3}{*}{ Sensibilização } & $\begin{array}{l}\text { 1. Promover cultura que questione os papéis tradicionais de gênero, } \\
\text { incentivando modelos de maternidade e paternidade mais igualitários, } \\
\text { incorporando a cultura da corresponsabilidade. }\end{array}$ & $\begin{array}{l}\text { Bolívia; Chile; } \\
\text { Equador; Uruguai }\end{array}$ \\
\hline & $\begin{array}{l}\text { 2. Promover campanhas educativas sobre a corresponsabilidade do trabalho } \\
\text { reprodutivo não remunerado, realizado tanto no âmbito do lar como no } \\
\text { comunitário. }\end{array}$ & Brasil; Honduras \\
\hline & $\begin{array}{l}\text { 3. Promover uma cultura que reconheça o direito ao cuidado, assim como a } \\
\text { obrigação de cuidar-se e cuidar, valorizando o trabalho de cuidado não } \\
\text { remunerado realizado pelas mulheres. }\end{array}$ & Chile \\
\hline
\end{tabular}

Fonte: Elaboração própria, a partir dos planos de cada país.

Apesar de ser uma análise inicial e dificultar afirmações mais gerais, ela parece indicar que houve uma preocupação dos governos vigentes no período, principalmente em tornar visível o aporte do trabalho não remunerado para o funcionamento do bem-estar e do sistema econômico dos países. Houve também forte preocupação em socializar esse trabalho, gerando mais responsabilidades masculinas e reforçando a necessidade de equipamentos públicos e comunitários.

As ações envolvendo os equipamentos continuaram bastante concentradas nas creches, enquanto os serviços de cuidado dos idosos e pessoas com deficiência foram previstos pela minoria dos planos analisados. Houve também pouquíssima preocupação com a socialização do trabalho doméstico, como alimentação e lavagem de roupas.

Além disso, a "crise do cuidado", como referida pela CEPAL, ainda não fez parte do horizonte de ações dos governos, pelo menos não nesses termos. Além desses desafios, há os relativos à implementação das ações que, muitas vezes, impactam significativamente os orçamentos e desafiam os interesses das empresas privadas - principalmente as que se referem a mudanças na legislação trabalhista - e têm sofrido rupturas nas atuais mudanças de governos. Além disso, apesar de conterem metas de redução das desigualdades de gênero, muitas vezes os planos não preveem orçamentos ou responsabilidades de outros ministérios para além dos órgãos de política para as mulheres.

Por fim, mesmo que alguns avanços estejam em curso, os sistemas de bem-estar desse período continuam calcados no trabalho não remunerado das mulheres no interior da família. Aumentar a participação do mercado no provimento do trabalho reprodutivo não é uma solução, como revelam as estratégias comunitárias de cuidado da década de 1990 na região. Nesse sentido, é imprescindível haver soluções públicas para esses problemas, de modo a contribuírem para a emancipação das mulheres e prepararem as sociedades latino-americanas para o crescimento das demandas de cuidado, que serão cada vez maiores no futuro. 


\section{Conclusões}

A literatura contemporânea do Estado de Bem-Estar Social foi desenvolvida de modo a garantir bases teóricas para a comparação dos diferentes regimes nos países desenvolvidos. A partir de EspingAndersen (1990), os regimes foram comparados segundo os níveis de desmercadorização e estratificação social, garantidos a partir do conjunto de políticas de proteção social. Posteriormente, com o estabelecimento do mainstream da área, as feministas passaram a refletir sobre a análise do Estado de Bem-Estar. Em um primeiro momento, o objetivo de inserção dessas teóricas era apontar os valores patriarcais em que se assentavam os Welfare States e, no segundo momento, algumas análises buscaram pensar os regimes de bem-estar a partir do seu impacto na vida das mulheres.

A renovada agenda social, adotada do início do século XXI a meados da segunda década, abriu uma nova questão teórica sobre como analisar as transformações em curso, a partir dos conceitos de EBES. Algumas novidades no sistema de proteção social da região indicaram tratar-se de um novo momento, apesar de suas semelhanças com os EBES europeus e as instituições sociais do desenvolvimentismo latino-americano. Nesse contexto, a análise dos regimes de bem-estar da região demonstrou que eles estiveram amplamente calcados na família, como principal provedora do bemestar. No interior da família, as mulheres é que são as grandes provedoras, ao exercerem a maior parte do trabalho não remunerado e de cuidado.

A crise do cuidado parece que será a tônica social do próximo período na região. As mulheres têm participação cada vez mais elevada nos trabalhos remunerados, a divisão sexual do trabalho continua rígida e aumentam as famílias monoparentais e a demanda da população que requer cuidados, devido ao seu envelhecimento, à manutenção das altas taxas de fecundidade e ao aumento das pessoas com doenças crônicas.

A análise dos planos nacionais de igualdade de gênero nos mostrou que, apesar da crise do cuidado ainda não ter sido mencionada neles pelos governos (com exceção do plano chileno), houve uma série de ações previstas para visibilizar e socializar o trabalho reprodutivo, mesmo tendo permanecido os desafios de implementação. A revisão da agenda social do ciclo progressista, atualmente em curso em muitos países da América Latina, parece estar renovando a legitimidade do familismo, ainda que novos estudos sejam necessários para compreender as transformações nos arranjos de provimento do bem-estar entre o mercado, o Estado e as famílias.

Garantir que os sistemas de bem-estar latino-americanos desafiem as desigualdades de gênero passa, necessariamente, por mudanças na forma como os trabalhos domésticos são divididos entre os membros das famílias e a efetivação e fortalecimento da participação do Estado nos trabalhos de reprodução da vida.

\section{Referências}

CARDOSO JR., José Celso. Fundamentos Sociais das Economias Pós-industriais: uma Resenha Crítica de Esping-Andersen. BIB, n. 56, p. 71-89, 2. Sem. 2003.

CEPAL. Panorama Social de America Latina. Santiago del Chile: Naciones Unidas, 2009.

CHILE. Plan de Igualdad entre mujeres y hombres 2010-2020. 2010. 
DRAIBE, Sonia; RIESCO, Manuel. Estado de Bem-Estar Social e estratégias de desenvolvimento na América Latina. Um novo desenvolvimentismo em gestação? Sociologias, ano 13, n. 27, p. 220 254, mai.-ago. 2011.

. El Estado de bienestar social en América Latina: una nueva estrategia de desarrollo.

Fundación Carolina. Documento de Trabajo n. 31, jan. 2009.

. Estado de bienestar, desarrollo económico y ciudadanía: algunas lecciones de la literatura contemporânea. CEPAL, Serie Estudios y Perspectivas, n. 55, ago. 2006.

ESPING-ANDERSEN, Gøsta. Social foundations of post-industrial economies. Oxford/New York: Oxford University Press, 1999.

. The three worlds of Welfare Capitalism. New Jersey: Princeton University Press, 1990.

FOX PIVEN, Frances. Ideology and the State: Women, Power and the Welfare State. In:

GORDON, Linda (Ed.). Women, the State and Welfare. Wisconsin: The University of Wisconsin Press, 1990.

FRANZONI, Juliana M. Regímenes de Bienestar en América Latina. Fundación Carolina. Documento de Trabajo n. 11, mai. 2007.

FRASER, Nancy. Las contradicciones del capital y los cuidados. New Left Review, n. 100, p. 111132, Sep.-Oct. 2016.

. Women, Welfare and the Politics of Need Interpretation. In: FRASER, Nancy. Unruly Practices: Power, Discourse, and Gender in Contemporary Social Theory. Minneapolis: University of Minnesota Press, 1989.

GORDON, Lisa. The New Feminist Scholarship on the Welfare State. In: GORDON, Linda (Ed.). Women, the State and Welfare. Wisconsin: The University of Wisconsin Press, 1990.

HIRATA, Helena. Teorias e práticas do care: estado sucinto da arte, dados de pesquisa e pontos em debate. In: FARIA, Nalu; MORENO, Renata (Orgs.). Cuidado, trabalho e autonomia das mulheres. São Paulo: Sempreviva Organização Feminista, 2010.

HIRATA, Helena; KERGOAT, Danièle. Novas configurações da divisão sexual do trabalho. Cadernos de Pesquisa, v. 37, n. 132, p. 595-609, set.-dez. 2007.

MATOS, Marlise; PARADIS, Clarisse. Desafios à despatriarcalização do Estado brasileiro. Cadernos Pagu, n. 43, p. 57-118, 2014.

MONTAÑO, Sonia. El trabajo de cuidado en América Latina. In: DURÁN, María Ángeles (Dir.). El trabajo del cuidado em América Latina y España. Madri: Fundación Carolina, 2011. Documento de Trabajo n. 54.

MYLES, John; QUADAGNO, Jill. Political Theories of the Welfare State. Social Service Review, v. 76, n. 1, p. 34-57, mar. 2002.

ORLOFF, Ann Shola. Gender and the Welfare State. Institute for Research on Poverty. Discussion Paper n. 1082, mar. 1996.

. Gender and the Social Rights of Citizenship: The Comparative Analysis of Gender Relations and Welfare States. American Sociological Review, v. 58, n. 3, p. 303-328, Jun. 1993.

PATEMAN, Carole. The Patriarchal Welfare State. In: PATEMAN, Carole. The disorder of Women: democracy, Feminism and Political Theory. Stanford: Stanford University Press, 1989. 
SAINSBURY, Diane. Gendering Welfare State. In: GOERTZ, Gary; MAZUR, Amy G. (Eds.). Politics, gender and concepts: theory and methodology. New York: Cambridge University Press, 2008.

. Gender, Equality and Welfare States. Cambridge: Cambridge University Press, 1996.

TRONTO, Joan C. Mulheres e cuidados: o que as feministas podem aprender sobre a moralidade a partir disso? In: JAGGAR, Alison M.; BORDO, Susan R. (Orgs.) Gênero, Corpo, Conhecimento. Rio de Janeiro: Editora Rosa dos Tempos, 1997.

\author{
Artigo recebido em: Maio/2016 \\ Artigo aceito em: Novembro/2019
}

Clarisse Goulart Paradis (clarisseparadis@gmail.com) é professora adjunta da Universidade da Integração Internacional da Lusofonia Afro-brasileira (UNILAB). Doutora em Ciência Política pela Universidade Federal de Minas Gerais (UFMG).

\title{
Os Desafios do Bem-estar na América Latina, as Políticas de Igualdade de Gênero e as Respostas Governamentais para a "Crise do Cuidado"
}

\begin{abstract}
Resumo. Os países latino-americanos enfrentaram profundas transformações sociais e demográficas nos últimos vinte anos, com a incorporação massiva das mulheres no trabalho remunerado, transformações no escopo da família nuclear e o envelhecimento de sua população. Essas transformações geram dilemas associados à relação entre o trabalho remunerado e não remunerado e à "crise do cuidado". Se houve uma renovação da agenda social entre o início do século e meados da sua segunda década, na América Latina, quais foram as percepções e respostas dos Estados a estas transformações? A partir do aporte da literatura sobre Estados de Bem-Estar Social, suas críticas feministas e adequações para pensar o contexto regional, serão analisados os planos nacionais de igualdade de gênero, com o objetivo de averiguar se e como os governos consideraram, valoraram e propuseram soluções para essas transformações. Conclui-se que para que os sistemas de bem-estar latino-americanos desafiem as desigualdades de gênero é necessário efetivar e fortalecer a participação do Estado na produção do viver.
\end{abstract}

Palavras-chave: Estado de Bem-Estar Social; Agenda Social Latino-Americana; Crise do Cuidado; Trabalho Não Remunerado; Planos Nacionais de Igualdade de Gênero.

\section{Challenges of Social Welfare in Latin America, Gender Equality Policies and Governmental Answers to the "Care Crisis"}

\begin{abstract}
Latin American countries have faced profound social and demographic transformations over the past twenty years, due to massive incorporation of women into paid work, changes in the scope of the nuclear family and the aging of their population. These transformations create dilemmas associated with the relationship between paid and unpaid work and the "care crisis". If there was a renewal of the social agenda from the beginning of the century to the middle of its second decade in Latin America, what were the perceptions and responses of states to these transformations? Stemming from the literature on Social Welfare States, their feminist critiques and their adaptations for thinking
\end{abstract}


about the regional context, analysis of national gender equality plans will be conducted in order to inquire if and how governments have considered, valued and proposed solutions to these transformations. The conclusion is that for Latin American welfare systems to challenge gender inequalities, it is necessary for state to effect and strengthen its participation in the production of life. Keywords: Welfare State; Latin American Social Agenda; Care Crisis; Unpaid Work; National Plans of Gender Equality. 